\title{
LA FOTOGRAFÍA COMO FUENTE DE INVESTIGACIÓN HISTÓRICO-ANTROPOLÓGICA. EL CASO DEL PROYECTO "CAMPO DE TRABALLO ARQUEOLÓXICO NO CASTRO GRANDE DE NEIXÓN (BOIRO, A CORUÑA)"1
}

\author{
PHOTOGRAPHY AS A HISTORIC AND \\ ANTHROPOLOGIC INVESTIGATION SOURCE, \\ THE CASE OF THE "CAMPO DE TRABALLO \\ ARQUEOLÓXICO NO CASTRO GRANDE DO \\ NEIXÓN" PROJECT (BOIRO, A CORUÑA)
}

\author{
JUAN MARTÍN DABEZIES ${ }^{2}$ \\ Laboratorio de Patrimonio (IEGPS-CSIC)
}

\section{Resumen}

En este artículo presentamos una propuesta metodológica para incluir las fotografías de álbumes familiares como fuente documental para el estudio de la cultura e historia de la parroquia de Cespón (Boiro, a Coruña). Se trata de una propuesta que se enmarca en un proyecto multidisciplinar en donde la complejidad de un paisaje cultural es abordado desde varias disciplinas, incluyendo a lo visual como una forma complementaria a las fuentes orales, materiales (arqueológicas) y escritas. La propuesta apunta a sistematizar el trabajo con las fotografías para que sea posible hacerle las preguntas necesarias y para su correcta conservación virtual.

Palabras clave

Metodología-fotografía-patrimonio.
Abstract

In this article we propose a methodological approach to include pictures of family albums as documentary source for the study of the culture and history of the parish of Cespón (Boiro, a Coruña). It is a proposal that is part of a multidisciplinary project where the complexity of a cultural landscape is addressed from various disciplines, including the visual as a complementary to the sources oral, materials (archeological) and written. The proposal proposes to systematize the work with the photographies so that it is possible to do the necessary questions to him and for their correct virtual conservation.

\section{Key words}

Methodology-photography-heritage.

${ }^{1}$ Recibido/Received 19.03.2010. Aceptado/Accepted 07.05.2010

2 Becario AECID. USC. Laboratorio de Patrimonio (IEGPS-CSIC). Contacto: juanmartin.dabezies@ rai.usc.es 


\section{INTRODUCCIÓN}

Este artículo plantea una reivindicación epistemológica de la fotografía como fuente de análisis. Pero propone hacerlo siguiendo un enfoque sistemático, de hecho exponemos los primeros pasos en ese manejo sistemático de la fotografías de álbumes familiares de vecinos de una parroquia gallega (Cespón, Borio, A Coruña).

En una primera parte de corte más bien teórico, desarrollaremos aspectos sobre la idoneidad de la fotografía como documento y todas las posibilidades que nos ofrece para el estudio de la cultura desde diversos puntos de vista. Luego planteamos algunas propuestas de análisis de las cuales tomamos los aspectos que consideramos más relevantes para nuestros propósitos de análisis, y desarrollamos la parte final del trabajo.

Esta parte final se centra en una propuesta metodológica que está en pleno desarrollo, aunque ya fue implementada en sus fases iniciales. El lector no se encontrará resultados interpretativos, sino más bien metodológicos. Consideramos interesante publicar estos desarrollos ya que se trata de una propuesta que está dando muy buenos resultados y cuya implementación permite incorporar una perspectiva que muchas veces no es considerada por enfoques más tradicionales.

\section{LA FOTOGRAFÍA EN UN SEGUNDO PLANO.}

Las imágenes son superficies que pretenden representar algo. En términos de comunicación, el significado de una imagen es el resultado de la confluencia de dos grandes intencionalidades, la del emisor y la del receptor. El receptor observa la imagen en un movimiento constante de recorrido de la misma, estableciendo significados. En ese tiempo de construcción de significados mediante ese scanning de la imagen, el tiempo se vuelve mágico (Flusser, 2002). En ese tiempo mágico se generan otras imágenes en el receptor producto de una narrativa propia de la imagen, la cual puede ser solamente asemejada en lo textual a lo que ocurre con la poesía (Achutti, 2004).

Este proceso de vivir en un tiempo mágico no linear, un tiempo mítico, fue linearizado con el surgimiento de la escritura. En un afán por aproximarse más al mundo concreto, el hombre termina alejándose más, dando origen a la textolatria (Flusser, 2002).

Esta primacía del texto sobre la imagen como lenguaje objetivo y puro de la ciencia, repercute en la relación de la imagen con las disciplinas encargadas de generar conocimiento científico, como es el caso de la Historia. De ahí sus proble- 
mas de identidad, generados por el trauma infantil sobre el debate de su naturaleza: ¿ciencia artística o arte inexacta? (Linhares, 2003).

Si consideramos que la historia como disciplina fue entendida inicialmente como género literario, el tema del desprecio por la imagen parece evidente. En un afán por consolidarse como disciplina científica, la Historia trabaja en base a fuentes escritas, generalmente documentos oficiales de orden institucional. Esta hegemonía de la fuente escrita y oficial, se genera en oposición al desprecio por la fuente visual. La textolatría se erige en oposición al analfabetismo visual (Maresca, 1998; Meneses, 2005; Knauss, 2006), no solo en Historia sino en todo el mundo de las Humanidades y Ciencias Sociales.

Este desprecio por el documento visual y en concreto por la fotografía, generó un vacío disciplinar en cuanto al abordaje de lo visual. Este vacío dio origen a un campo interdisciplinar denominado "estudios visuales" caracterizados por el objeto "cultura visual", el cual surgió inicialmente en Estados Unidos en la década de 1990. Este campo está conformado por el análisis artístico, antropológico, histórico, semiótico, etc. (Knauss, 2006).

\section{ESTADO ACTUAL DE LA TEORIZACIÓN SOBRE FOTOGRAFÍA.}

Los usos de la fotografía han variado de acuerdo a diversas circunstancias técnicas y económicas (Linhares, 2003; Sanatella, 2005), y a su vez las concepciones respecto a la fotografía también han cambiado, aunque a veces se entremezclan (Dubois, 1993).

Luego del debate sobre su naturaleza entre 1820 y 1865 (¿qué era esta nueva forma de representar la realidad?, ¿se trataba de un ataque a los movimiento pictóricos o de un complemento?, ¿de una expresión artística para retratar la realidad o de una técnica de domesticar la naturaleza?), a finales del siglo XIX, comienzan a bajarse los costes y la complejidad de la técnica.

La fotografía se populariza, pasando de la aristocracia y la alta burguesía a las camadas populares, sentándose las bases para la fotografía comercial. Se multiplican los estudios fotográficos y surgen los primeros fotógrafos móviles. Los individuos y los grupos sociales comienzan a fotografiarse como forma de auto-representación. En estas representaciones, con formato de retrato, existen padrones de representación que permiten analizar diversos aspectos históricos y antropológicos de estos grupos (Linhares, 2003).

Si bien entrado el siglo XX ya son diversos los usos de la fotografía, destacan el uso y circulación de cartones postales para promover la modernización de las 
ciudades, y de los principales monumentos con los que se identificaba la burguesía de la Belle Époque. Uno de los usos más importantes de la fotografía en cuanto a su consumo es el de la prensa. Ya desde principios del siglo XX se realizaron fotorreportajes, en donde se quería transmitir un mensaje para lograr un impacto social. Tal es el caso de los usos político-ideológicos de las fotografías de la muerte, en los casos de Che Guevara o las fotos de la pobreza o minorías para realizar valoraciones moralistas burguesas (Linhares, 2003).

Si queremos analizar algunas particularidades de la fotografía, debemos adoptar un enfoque que tenga en cuenta lo visible y lo invisible de la fotografía, en cuanto a su sincronía y a su diacronía. Tal es la propuesta de Meneses (2005), en la cual propone analizar la fotografía en relación a tres aspectos: lo visual, lo visible y la visión.

Lo visual se refiere a los sistemas de comunicación visual, entendiendo por éstos las instituciones visuales o los soportes institucionales de los sistemas visuales (escuela, empresa, museo, etc), condiciones técnicas, sociales y culturales de producción, circulación y consumo, y la acción de los recursos y de los productos visuales. Esta identificación, corresponde a la esfera de la iconósfera, o sea, el conjunto de imágenes guía de un grupo social en un momento dado (Meneses, 2005).

Lo visible (y lo invisible) representa el dominio del poder y el control, o sea la dinámica de ver, ser visto, la visibilidad y la invisibilidad en los grupos sociales. Casos que ilustran esta dinámica son los estudiados por Elías sobre la etiqueta como sistema visual, el panóptico controlador, etc. (Meneses, 2005).

Otro caso de lo visible son la espectacularización de la sociedad y el oculocentrismo. La primera se refiere a la impregnación de la imagen en la cotidianeidad de las relaciones humanas, mientras que el segundo hace referencia al privilegio epistemológico de la visión en la modernidad (Meneses, 2005).

La visión se refiere a los instrumentos y técnicas de observación, el observador y sus roles, los modelos y las formas de mirar (mirar de reojo, mirada firme, mirar patriarcal, etc). Esta introducción del observador, conlleva cambios epistémicos en los modelos de visualidad, evidenciando el carácter coyuntural e histórico de la visión (Meneses, 2005).

Estas dimensiones de la fotografía se corresponden con la visión de Kossoy (2001) en la cual la fotografía es deconstruida, tornando más fácil la reconstrucción de la historia de vida de la misma para asó sentar las bases de cualquier propuesta metodológica.

Kossoy (2001) propone una deconstrucción arqueológica de la fotografía, en donde la imagen que se puede ver en la fotografía es una segunda realidad de la misma. La vida material de la fotografía como documento está generada a partir de tres elementos: el asunto, la tecnología y la técnica, y por último, el fotógrafo. 
La fotografía es un recorte espacio temporal caracterizado por la fragmentación y el congelamiento, en donde está presente la realidad del referente (algo inevitable para el índice), la cual será suplantada por la realidad del documento. Existe una transposición de realidades, determinada por la naturaleza del referente (Kossoy, 2001). Este pensamiento tiene implícito un cambio de contexto, aspecto inevitable de toda la cultura material generado en un tiempo pasado (o por lo menos en un contexto diferente), y que llega a nuestros días con diversos valores (Mauad, 2004).

Asumir estos postulados nos posibilita andar el camino inverso, o sea recorrer un camino arqueológico, y poder entender aspectos sobre el contexto de producción de la fotografía, entendiendo a éste como el contexto del referente y el contexto del fotógrafo. A su vez es necesario entender el contexto actual de la fotografía como documento, o sea el contexto arqueológico al decir de Schiffer (1972). Este contexto hace referencia al lugar donde se encuentran y a los circuitos recorridos, los cuales son fundamentales en la atribución de significados variables. Esto significa entender que la fotografía no tiene un significado absoluto, a pesar de su indicialidad, su significado está en parte determinado por su historia de vida como objeto social, como cosa. Esas cosas con significado son las que el investigador utilizará como documento histórico, por lo cual debe considerar dónde estuvieron, pero además observar su lugar actual, si están en un museo, cómo están dispuestas, si están en una colección particular, si son parte de una muestra, etc. (Kossoy, 2001).

Como señala Kossoy (2001), la inmaterialidad también debe ser considerada, y esto significa integrar las variables antropológicas e históricas respecto a la producción de la fotografía, o sea el imaginario y la subjetividad del fotógrafo y del referente, del contexto arqueológico (promotor cultural, empresario, funcionario público, político, etc) y del investigador. A su vez nos resta otra subjetividad e imaginario que es la del lector, en el sentido de consumidor de la información obtenida por el investigador a partir de su investigación, en la cual debe jugar con varios niveles de interpretación (Kossoy, 2001).

Ordenando un poco estas afirmaciones y explicitando la idea de la fotografía como productora de sentido, o sea como parte activa de la trama social, estos aspectos tratados pueden agruparse en la cuestión de la producción, la cuestión de la recepción y la cuestión del producto (Mauad, 2004).

\section{HISTORIA E IMAGEN. PROPUESTAS METODOLÓGICAS.}

En base a estas consideraciones y reconstrucciones sobre la fotografía como documento histórico, desde la historia existen propuestas concretas. Sobre el análisis de fotografías del pasado y del presente, ya existen ciertos postulados básicos 
que Mauad (2004) expone de forma muy clara. El estudio de documentos visuales como es el caso de la fotografía, exige el trabajo con un conjunto de imágenes. Tal cual ocurre con la excavación arqueológica, cuyos dos principios básicos son la estratigrafía y la asociación, o sea la observación diacrónica y la asociación espacial sincrónica del material, las fotografías adquieren sentido en el conjunto.

Otro principio es el de intertextualidad, el cual supone que para entender la fotografía como texto, se deben entender otros textos que permitan entender la textualidad de la época (Mauad, 2004).

El trabajo transdisciplinar es el tercer principio que señala Mauad (2004). Este principio consiste en ser conscientes de la complejidad y las posibilidades de esta apertura epistemológica del documento visual, que da lugar a los estudios visuales, en donde las diversas aproximaciones disciplinares articulando interpretaciones (diferencia fundamental con la interdisciplinariedad) son fundamentales e inevitables.

La primera propuesta metodológica para el estudio de la fotografía que presentaré es la de Kossoy (2001). Su estrategia para la interpretación de fotografías como documento histórico, consiste en separar el análisis en dos momentos: análisis iconográfico y análisis iconológico, el primero más preocupado por lo exterior al documento y el segundo más por el interior.

El primer análisis denominado como "una verdadera arqueología del documento" (Kossoy, 2001: 58), consiste en una preocupación por la información implícita y explícita de la imagen. O sea reconstruir el proceso que dio origen a esa cosa fotografía: lugar, tecnología utilizada, fotógrafo, fecha, etc. También se debe realizar un detallado análisis icónico del contenido del documento (Kossoy, 2001).

En un segundo paso, el análisis iconológico consiste en interpretar el contenido profundo del documento. Si bien Kossoy señala que no existe una regla para tal interpretación, propone dos caminos: entender la historia del asunto y desmontar las condiciones de producción (Kossoy, 2001).

Otro enfoque metodológico, presentado en este caso para el análisis de álbumes de la ciudad de San Pablo, es el de Lima y Carvalho (1997), en donde la propuesta consiste en llevar a cabo un tratamiento individual de cada imagen, en la cual se sistematizan los atributos icónicos y formales. Los descriptores icónicos son los elementos figurativos y espaciales que comprenden aspectos del paisaje, mientras que lo formales son elementos propios de la técnica de la fotografía, como ser: encuadramiento, arreglo de los elementos, articulación de planos, efectos y estructura.

Otro movimiento que proponen estas autoras es el de ordenar las fotografías de acuerdo a padrones temático-visuales. Las autoras describen 9 padrones: retrato, 
circulación urbana, figurista (personas realizando alguna actividad), diversidad (tomas abarcativas del tejido urbano), coexistencia (en fotos hasta 1950, en donde se asocian diversos motivos con temporalidades variables), intensidad (para fotos hasta 1950, refiere a la repetición de un único elemento), cambio (representaciones del cambio en la ciudad), paisajístico (naturaleza) y ordenamiento (para fotos de principios del siglo XX, donde se presenta una organización espacial destinada al uso residencial) (Lima y Carvalho, 1997).

Miriam Moreira Leite (2001) también nos presenta una propuesta metodológica que consiste fundamentalmente en estudiar en primer lugar los aspectos referentes al contexto producción de la imagen, para luego estudiar el contenido interno de las imágenes. El tercer momento sería la seriación o secuenciación de las fotografías de acuerdo a los criterios de interés del investigador (Moreira, 2001).

Entre las variables que deben ser tenidas en cuenta, la autora señala que las tecnológicas y las sociales son fundamentales. Dentro de las tecnológicas coloca la iluminación, el lugar de toma de la fotografía, el padrón espacial, proximidad, direcciones del plano, etc. (Moreira, 2001).

Para terminar con la exposición de metodologías de análisis de la fotografía, se presentarán la propuesta de Mauad (2004), el cual es un método histórico-semiótico, encarando la fotografía desde su función comunicativa.

Las fotografías deben ser analizadas interna y externamente, y organizadas en series. La fotografía debe ser entendida como parte de la trama social, como producto y productora de sentido, codificada y codificadora cultural. También debe entenderse su indicialidad y sus usos sociales, reales o potenciales (Mauad, 2004). O sea, además de entender el qué, entender el para qué, e intentar responder el por qué, del qué y del para qué (y sus por qué no).

Para responder estas cuestiones, la propuesta consiste en vincular el plano de contenido, o sea la relación de los elementos de la fotografía con el contexto, y el de expresión, es decir, el corte temático y temporal (Mauad, 2004).

\section{MARCO DE TRABAJO.}

El trabajo se llevó a cabo en el marco del proyecto "Campo de traballo arqueolóxico no Castro Grande de Neixón (Boiro, A Coruña)", desarrollado en el Concello de Boiro en la provincia de A Coruña, Galicia. Este artículo se centra en el trabajo desarrollado durante el año 2008, a cargo del Laboratorio de Patrimonio (IEGPS-CSIC-España). El Castro de Neixón es parte de un paisaje arqueológico regional (ver Figura 1 y Figura 2 ) y articula una serie de valores patrimoniales pasa- 
dos y presentes. Esta polisemia de valores, es la base de un proyecto multidimensional, el cual es el marco de este trabajo.

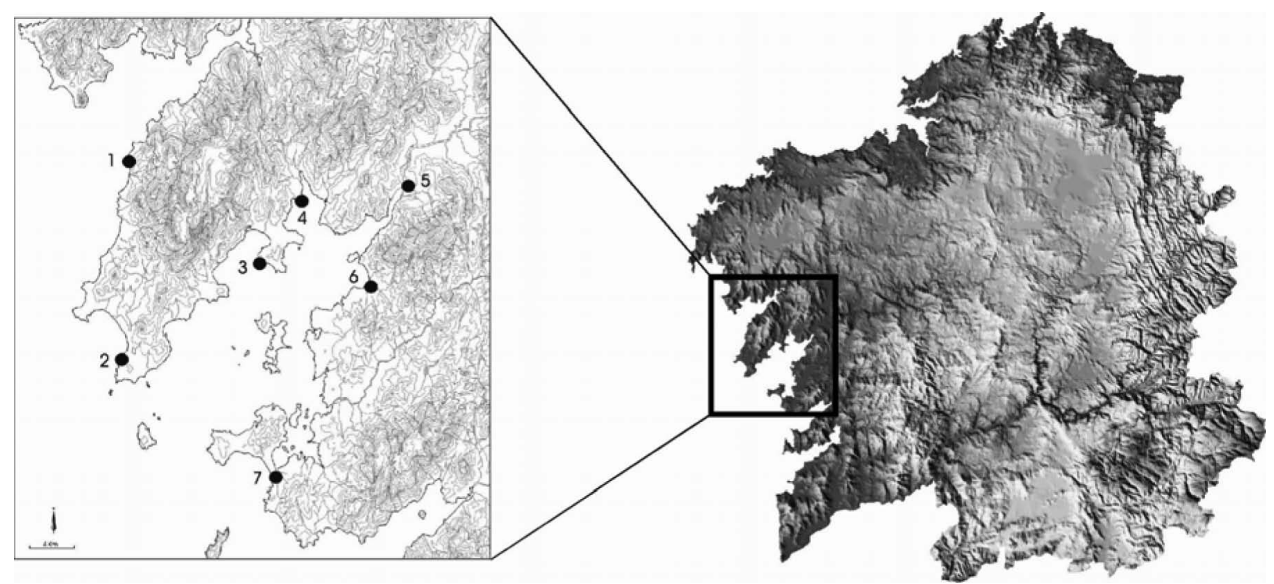

Figura 1. Ubicación del Sitio Os Castros de Neixon. Observense otros castros excavados recientemente en la península de Barbanza y Ría de Arousa: 1. Baroña; 2. Porto Baixo; 3. O Achadizo; 4. Castros de Neixón; 5. Torres do oeste; 6. Alobre y 7: A Lanzada.

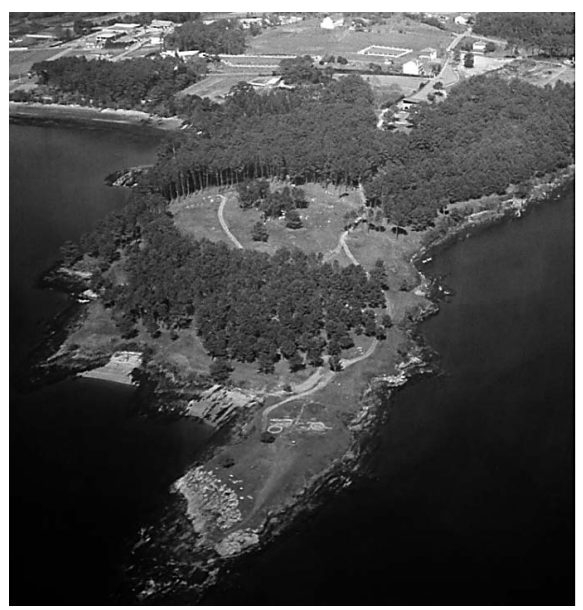

Figura 2. Foto panorámica del Castro de Neixón.

El proyecto define sus actividades como:

"un campo de traballo de ámbito internacional e modalidade arqueolóxica (Aula de Arqueoloxía). Intervención arqueolóxica: escavación e consolidación das ruínas 
e restos exhumados, no castro do Neixón, para a súa revalorización como recurso cultural, promovendo a creación dunha aula de arqueoloxía e posibilitando visitas culturais ás ruínas" (Ayán, et al., 2008: 6).

Con esta iniciativa, las instituciones continúan con el potenciamiento y puesta en valor de este espacio simbólico. El campo de trabajo se concibió como una estrategia de promoción de turismo cultural y de desarrollo sostenible en la zona (Ayán, 2008b).

Este paisaje multidimensional de los Castros de Neixón, es un espacio que ha tenido múltiples significados a lo largo de tres mil años, que confluyen en un Paisaje Cultural actual muy polisémico (Ayán, 2008a).

En este sentido pueden diferenciarse 5 tipos de significados que si bien están entrelazados, pueden discriminarse como significaciones particulares (Ayán, et al., 2008; Ayán, 2008c):

1. Como mito historiográfico de la Arqueología galleguista: las intervenciones de Bouza Brey y de López Cuevillas en el Castro Pequeno de Neixón en 1925, fueron las primeras excavaciones de carácter científico realizadas en España, que por otra parte, sentaron las bases de la interpretación celtista del pasado protohistórico de Galicia.

2. Se trata de un yacimiento arqueológico de la Protohistoria y Arqueología Antigua de Galicia. Estos Castros estuvieron habitados durante 1500 años, permitiendo comprender el desarrollo de la cultura castreña y de la romanización en la zona entre los siglos VIII a. C. y IV d.C. También fue un lugar clave en lo que respecta a la relaciones entre el mundo atlántico y el mediterráneo, ya que era un enclave comercial de interés de los comerciantes cartagineses.

3. Es también un espacio económico dentro de una parroquia paleomedieval, en donde se transforma en un espacio no habitacional del cual se extraen diversos recursos como leña, vegetales, piedra, pesca y mariscos.

4. Espacio para actividades ilícitas como fondeadero para el contrabando de tabaco, básicamente el desembarco y el almacenamiento en búnkers subterráneos. Con funcionalidad similar posteriormente a la legalización del tabaco, este espacio fue (y es) utilizado para el narcotráfico.

5. Como escenarios simbólicos de rituales católicos y paganos (romerías, procesiones, ceremonias religiosas). El primer fin de semana de agosto se celebra una de las fiestas más importantes de la zona, emplazada al lado del parapeto del Castro Grande. 
Este sitio también es parte del paisaje bélico de la Guerra Civil española y (especialmente) de los primeros años de la dictadura franquista. En este período se generó un paisaje particular con estructuras, elementos y relaciones, que formaban parte de una dinámica represiva y de resistencia particular. Uno de estos aspectos materiales que tuvieron mayor notoriedad fueron los campos de concentración que existieron a escasa distancia de de este espacio, como es el caso del Campo de Rianxo a unos 5 kms y el de Muros, a unos 60 kms (Ayán, et al., 2008).

Si bien en la zona exacta de la península donde están emplazados los Castros, no existen manifestaciones materiales de este paisaje bélico y represor, en la memoria local esto está fuertemente presente, más que nada en ciertas franjas etarias (mayores de 70 años), que han vivido muy de cerca este período (Ayán, et al., 2008).

\section{LA FOTOGRAFÍA HISTÓRICA COMO DOCUMENTO HISTÓRICO- ANTROPOLÓGICO. PROPUESTA METODOLÓGICA.}

Desde hace ya tiempo se ha venido trabajando en la línea de la microhistoria, un enfoque que entremezcla una mirada antropológica y una historiográfica, utilizando como fuente de trabajo el testimonio oral en base a diversas modalidades de entrevista para abordar aspectos de la memoria oral de la zona (Ayán, 2008a; 2008c). Luego de varios años de trabajo en la zona de Neixón, surge la necesidad de integrar las fotografías que forman parte de los álbumes familiares y de hacerlo sistemáticamente, de forma que sea posible ordenar el material para poder realizarle las preguntas de investigación adecuadas hoy y mañana. El trabajo tiene una perspectiva patrimonial, en el sentido que se tata de documentos materiales que están en muy mal estado y que en ocasiones corren serios riesgos de degradación por no estar conservados en condiciones adecuadas.

El objetivo de este desarrollo metodológico fue poder incluir un nuevo enfoque sobre diversas dimensiones significativas de este paisaje, como es el caso de la dimensión de espacio económico, espacio simbólico y el período de la Guerra Civil y el Franquismo (Ayán, et al., 2008).

La estrategia de trabajo se basó en aprovechar las redes sociales que el proyecto ha generado en la zona luego de más de 5 años de trabajo ${ }^{3}$. El enfoque histórico-antropológico seguido, en base al cual se establecieron vínculos con

3 Una institución que resultó clave para esto fue la Asociación de Veciños de Cespón, con quienes se trabajó permanentemente en la búsqueda de colecciones familiares. 
varios de los informantes, permitió tener un buen acercamiento a las colecciones familiares.

El objetivo concreto de este desarrollo metodológico fue incorporar a la fotografía como fuente de trabajo en base al cual llevar a cabo nuestros análisis e interpretaciones. Las fotografías fueron entendidas como un objeto material con una biografía determinada (material e inmaterial) y con una multiplicidad de significados en la sincronía y diacronía. Por tal motivo se elaboró una metodología de análisis que combina las propuestas mencionadas anteriormente (Lima y Carvalho, 1997; Kossoy, 2001; Mauad, 2004; Moreira, 2001), enfatizando la dimensión antropológica, en base a la cual se pretende acceder a una trama de significados que están por detrás de un análisis meramente formal o semiótico.

La metodología de trabajo comenzó con el diseño de una ficha en la cual se sistematizaron todas las fotografías. Una vez establecidos los contactos, se llevó a cabo la difusión de la actividad en la zona y se comenzó con el trabajo. El procedimiento de llenado de la ficha consta de dos etapas:

1. Digitalización de la fotografía papel: se reúnen las fotografías y se digitalizan con un escáner manual. La fotografía debe ser escaneada por ambos lados, ya que pueden existir datos de enorme importancia en el reverso de la fotografía (anotaciones personales, fechas, nombres del estudio que realizó la fotografía, nombres del papel fotográfico, etc.). El escaneo debe realizarse a alta resolución (300 dpi como mínimo). Esta fotografía debe ser codificada con el código utilizado por el LaPa para las fotografías de registro. (Martínez, 1997). Luego, se debe completar una tabla en donde se realiza un descripción somera de cada fotografía (Martínez, 1997), con los datos de la persona propietaria de la fotografía, para que sea posible contactarla para realizar la siguiente etapa.

2. Entrevista: esta etapa apunta a acceder a ciertos datos que pueden estar por detrás de los elementos visibles de la fotografía. Luego que la fotografía es digitalizada, se debe hacer una copia a baja resolución (72 dpi) que formará parte de esta ficha. Se deberá concretar una entrevista con el propietario de la fotografía, el fotógrafo, una persona que aparezca fotografiada o que haya estado en el momento de la toma (o con quien se considere necesario para cumplir el objetivo establecido de esta etapa), para completar los campos a los cuales no se tiene acceso mediante el análisis formal o semiótico (o bien para buscar un reinterpretación de los datos $)^{4}$.

${ }^{4}$ La entrevista no tiene por que ser pautada para este objetivo en concreto, sino que puede realizarse en el marco de otro objetivo. 
Actualmente hemos completado la primera etapa de trabajo y estamos en la fase de entrevistas para completar todos los otros datos que necesitamos. Ya se han digitalizado más de 500 fotografías, y aún seguimos en contacto con nuestros informantes para engrosar el archivo.

La ficha de trabajo fue denominada Fotografía Histórica (abreviada como FH) la cual cuenta con los siguientes campos:

- Datos formales del proyecto: se trata de una serie de campos de uso interno del LaPa:

- Código interno

- Nombre

- Fecha de ejecución

- Código oficial

- Código de la empresa

- Fecha en que fue Informatizado

- Fecha de revisión

- Datos del autor de la digitalización y entrevista: se coloca el primer nombre y primer apellido del autor de la digitalización y también se debe indicar a continuación el primer nombre y primer apellido de quien realizó la entrevista. Se puede colocar también la inicial del segundo nombre separada con un "punto". A continuación del apellido se debe colocar entre paréntesis el código DI a quien digitalizó, y el código EN, a quien realizó la entrevista posterior. Si fue la misma persona se le coloca después del apellido y dentro de un mismo paréntesis ambos códigos separados por un guión. Si actuaron dos personas, se debe seguir el mismo procedimiento, separando cada nombre de la persona con la letra "y". Si son más de dos se separan los nombres con una "coma", y la separación del último con "y". Ejemplo: Autor/es: Juan M. Dabezies (DI-EN), Xurxo Ayán (EN) y Pedro Fermin (EN).

- Vinculación de la ficha: se deben incluir las entidades de documentación que existen vinculadas a la entrevista o al momento de la digitalización. Los vínculos se indican con el código correspondiente de cada entidad. Se deben separar con una "coma", y en el caso de existir una vinculación a varias entidades cuyos dígitos finales son continuados, se separa el primero y el último con guión. Ejemplo: Vinculado a: FO4200X53-58, AU061102Q01, AU061202Q02.

- Datos del informante:

- Nombre: se coloca el primer nombre y primer apellido del informante.

También se puede colocar entre paréntesis el apodo de la persona. Si 
son dos informantes, se debe seguir el mismo procedimeinto, separando cada nombre de la persona con la letra "y". Si son más de dos se separan los nombres con una "coma", y la separación del último con "y". Ejemplo: Nombre: José Montes (Tito), Maria N. Robles y Pedro Robles.

- Edad aproximada: se puede colocar una cifra aproximada o dos valores (máximo y mínimo) separados por un guión, entre los cuales se considere que está la edad del informante. Si son varias personas, se debe seguir el mismo orden en el que se anotaron los nombres.

- Lugar al que pertenece: se debe colocar el lugar lo más detallado posible.

- Sexo: indicar masculino o femenino.

- Datos formales de la fotografía: son datos de la fotografía papel, que nos permiten tener un acercamiento a la fotografía como objeto material.

- Tamaño real de la fotografía papel: dimensiones de lado (en cms). Se deben separar ambos valores con una " $x$ ".

- Disponibilidad de la fotografía papel: refiere a si la fotografía forma parte de un acervo privado o público. Se indica con el siguiente código: PU si es pública y PR si es privada.

- Ubicación actual: refiere al lugar en donde la fotografía se encuentra. Se debe mencionar lo más detallado posible, y también se deben colocar datos de contacto de ese lugar.

- Autor: refiere al autor de la fotografía.

- Lugar al que refiere la fotografía: se debe indicar el lugar en donde fue tomada la fotografía.

- Vista de la fotografía: se debe insertar la digitalización de la fotografía en baja resolución (72 dpi). Se debe colocar la digitalización de ambos lados de la fotografía (derecho y revés). A su vez se coloca el código de la fotografía digitalizada en alta calidad (300 dpi), en su carácter de entidad documental.

- Descripción de la fotografía: consiste en una descripción concreta y escueta de aspectos que no pueden apreciarse mediante el análisis visual de la fotografía. Los aspectos que deben estar presentes, aunque no en exclusividad, son: identificación de los elementos presentes (de izquierda a derecha, y de abajo a arriba), motivo por el que se tomó la fotografía, los lugares por donde circuló de la fotografía. También se pueden mencionar otros aspectos relevantes para la investigación.

- Otros datos: este campo apunta a incluir aquellos datos que no fueron contemplados en los campos anteriores. 


\section{CONCLUSIONES}

La fotografía es un instrumento fundamental para el registro en Antropología, Arqueología, Historia u otras disciplinas. Pero además de ser un elemento muy importante para los investigadores, lo es también para las personas que estudiamos. Cada fotografía además de representar algo, encierra intenciones de esa persona que quiso representar ese algo en un documento fotográfico. A su vez no todas las fotografías tienen la misma importancia para nuestros informantes. Unas estarán guardadas en el fondo de un cajón y otras estarán colgadas en la pared o en un marco fotográfico sobre un mueble con mucha visibilidad en la sala. Esto implica que las fotografías deben ser estudiadas no solo desde un punto de vista semiótico, sino también desde uno histórico, arqueológico y antropológico. Todas esas dimensiones es nuestra intención abordar con esta nueva herramienta metodológica.

El trabajo presenta ciertas dificultades prácticas y plantea problemas éticos. Las dificultades están vinculadas a la complejidad de digitalizar las fotografías en lugares con problemas de acceso a los recursos y de movilidad de los escáneres necesarios. Desde el punto de vista ético, se trata de documentos que los informantes nos han cedido con total desinterés, pero que debemos respetar a la hora de su manejo. Tal como sucede con las entrevistas o con otros tipos de documentos con implicancias personales o emocionales, las posibilidades de manejo deben estar muy claras para que no haya ningún tipo de problema entre las partes. Por esta razón en un principio solicitamos una autorización verbal, que en la fase de entrevistas estamos procediendo a materializar en un documento escrito que quede como constancia de las posibilidades de uso de esas fotografías.

El desarrollo de una ficha de trabajo que objetive todos los aspectos teóricos que consideramos relevantes, es algo fundamental al momento de establecer los mínimos necesarios para comprender estos documentos entre varios investigadores. Por supuesto que puede ocurrir que en la entrevista se destaquen ciertos temas que son de gran interés para el proyecto en curso, pero éstos aspectos no deben ser incluidos indiscriminadamente en las fichas de trabajo, sino que se debe apuntar a incluir los mínimos de información necesarios para poder compartir esa información con otros investigadores o utilizarla posteriormente por uno mismo. Debemos considerar que estos documentos son en sí mismos patrimonio. 


\section{BIBLIOGRAFÍA}

ACHUTTI, L. E. 2004. Fotoetnografía da Biblioteca Jardim. Porto Alegre: Editora da UFRGS/Tomo editorial.

AYÁN, X. 2008a. Microhistoria da Punta de Neixón: de espazo natural a paisaxe cultural. In: Actas de los I Encontros Arqueolóxicos de Barbanza. Boiro: Consello de Boiro, Xunta de Galicia. CD ROOM.

AYÁN, X. 2008b. O proxecto arqueolóxico Os Castros de Neixón (Boiro, A Coruña): o campo de trabalho como ferramenta para a posta en valor do Patrimonio. In: Actas del Seminario A Cultura Castreja: Acçôes e estrategias para o seu aproveitamento cultural. Santiago de Compostela: Xunta de Galicia. pp. 95-105

AYÁN, X. 2008c. Os Castros de Neixón II: de espazo natural a paisaxe cultural. Noia: Toxosoutos.

AYÁN, X.; FERMIN, P.; DABEZIES, J. M. 2008. Proyecto de Escavación arqueolóxica no Castro Grande de Neixón (Boiro, A Coruña). Santiago de Compostela: LaPa (IEGPS-CSIC).

DUBOIS, P. 1993. O ato fotográfico e outros ensaios. Campinas: Papirus.

FLUSSER, V. 2002. Filosofia da caixa-preta. Ensaios para uma futura filosofia da fotografia. Rio de Janeiro: Relumé Dumará.

KNAUSS, P. 2006. O desafio de fazer História com imagens: arte e cultura visual. Art Cultura , 8 (12). Pp 97-115.

KOSSOY, B. Fotografía e Historia. Buenos Aires: La Marca. 2001.

LIMA, S. y CARVALHO, V. 1997. Fotografía e cidade: da razão urbana á lógica do consumo: álbums da cidade de São Paulo, 1887-1954. São Paulo: Mercado das Letras. FAPESP.

LINHARES, M. 2003. Tradição e modernidade na mira dos fotógrafos. In: História e fotografia Belo Horizonte: Autêntica. pp. 37-73.

MARESCA, S. 1998. Sobre desafios lançados pela fotografia ás Ciências Sociais. In: L. ACHUTTI, Ensaios sobre o fotográfico Porto Alegre: Unidade Editorial. pp. 115-118.

MARTÍNEZ, M. 1997. Contribución a un Sistema de Registro de Yacimientos Arqueológicos en Galicia. Santiago de Compostela CAPA 2.: Grupo de Investigación en Arqueología del Paisaje, Universidade de Santiago de Compostela.

MAUAD, A. 2004. Fotografía e historia: possibilidades de análise. In: M. CIAVATTA, \& N. ALVES, A leitura de imagens na pesquisa social. Historia, comunicação e educação. São Paulo: Cortez.

MENESES, U. 2005. Rumo a uma Historia Visual. In: P. MARTINS, V. ECKERT, \& P. NAVEZ, $O$ imaginário é o poético nas Ciências Sociais San Pablo: EDUSC. pp. 33-56.

MOREIRA, M. 2001. Retratos de família. Leitura da fotografia histórica. San Pablo: Edusp.

SANATELLA, L. 2005. Os três paradigmas da imagen. In: E. SAMAIN, O fotográfico São Paulo: Hucitec. pp. 295-307.

SCHIFFER, M. 1972. Archeological context and systemic context. American Antiquity, 37 (2). Pp 156-165. 